\title{
Cal Poly and the Bank of America/Merrill Lynch Low Income Housing Challenge
}

\author{
Loulie Brown \\ PhD, Lecturer CRP-Cal Poly (201 1/12). She resides in Portland, Oregon where \\ she is teaching at Portland State and involved in neighborhood projects.
}

\begin{abstract}
In 2012, for the second year in a row, a Cal Poly team took first place in the Bank of America/Merrill Lynch Low Income Housing Challenge for graduate students. Lecturer Loulie Brown writes about the competition, her involvement supervising Cal Poly's interdisciplinary teams, and this year's entries.
\end{abstract}

\begin{abstract}
Initiated in 1992 by its Community Development Banking Group, the Bank of America/Merrill Lynch Low Income Housing Challenge is a unique opportunity for both graduate and undergraduate students to participate in an affordable housing development project. The purpose of the Housing Challenge is twofold: to introduce students to the intricacies of sustainable affordable housing development and also to the demands of working in cooperation across disciplines by engaging them in a project with a legitimate site, a developer partner, realistic financing problems, design, and project development constraints. The project culminates in student presentations to a jury of architects, developers, financiers, and housing advocates at the Bank of America's offices in San Francisco. The challenge is open to students from California universities. The 2012 participants included teams from Cal Poly San Luis Obispo, UC Berkeley, and UC Irvine.
\end{abstract}

Student teams are formed at the beginning of the Winter Term, and their first task is to find a developer partner and a site that is either slated for development or has great potential for development. The site is either selected by the developer or designated as a priority location by a local jurisdiction. In the remainder of term, the bulk of the work includes research into potential developer partners, local entitlements, green building strategies (now a key requirement for publicly financed affordable housing), and neighborhood outreach to inform budding design ideas. Just as Winter Term comes to a close, each participating team is required to prepare a preliminary project proposal that includes development financing, planning and zoning information, a community outreach plan and schematic building plans. The purpose of the preliminary submission is to get feedback from the Housing Challenge jury members, which teams can incorporate into their final proposals.

During Spring Term, weekly meetings ramp up as teams hone details of their projects, incorporate jury and developer-partner feedback, and come to terms with building sizes, site configuration, financing requirements for green building, in addition to visiting their sites to get a better feel of the physical and social contexts in which they are working. At this point in the de- sign process, each team realizes the interdependence of each member's roles: scheduling, finance, and code requirements demand that each member clarify their positions to accommodate the different sets of priorities. The final submission, due in mid-May, represents the efforts of students to think through the many regulatory, design, social, and economic issues that compose low-income housing development.

\section{Housing Challenge}

Having participated in the Housing Challenge since its inception, Cal Poly teams have produced several winning projects including 2011's Entrada Ranch, located on Los Osos Valley Road in San Luis Obispo, and designed with the collaboration of developer Clint Pearce of Madonna Enterprises. Given Cal Poly's history of success, there was much student interest in the 2012 Housing Challenge. Under the guidance of CRP Department Chair Hemata Dandekar and Lecturer Loulie Brown, Cal Poly fielded two teams from the Architecture, Business Administration, City and Regional Planning, Construction Management, and Landscape Architecture departments.

Each Cal Poly team chose a unique approach to the project: one group chose to work with a non-profit developer on a relatively small site situated in a primarily residential neighborhood, and the other group chose to work with a for-profit developer on a larger urban infill site. Their proposal compendiums consisted of schematic site plans, floor plans, elevations, renderings, and detailed descriptions of project finance, construction schedules, community outreach, and existing and future neighborhood amenities. The teams also developed websites and videos posted on YouTube.

\section{Team PLAN: Alere in Inglewood}

Team PLAN (Poly Led Affordable Neighborhoods) was comprised of Kyle Mendizibal and Allie Freund (Architecture), Jake Hummel (Business Administration), David Eng, Lisa Elgin, Brent Gibbons, and Shanna Hurley (CRP), and Emily Poole and Carlos Krinsky (Construction Management). They chose to work on a site in Inglewood California, and their developer partner was 
PATH Ventures, an L.A. based non-profit that develops permanent supportive housing for very low-income people, many of whom are transitioning from homelessness. The 32,000 square foot site is located at the corner of South Eucalyptus and Lime Streets in a residential neighborhood near downtown Inglewood. It is one of only four currently vacant sites in all of Inglewood and also happens to be directly below one of LAX's main flight paths.

One of the greatest challenges for Team PLAN in siting their project proposal, named Alere, which translates to the word nurture in Latin, was to integrate it into the existing neighborhood. Previous attempts to develop the property with multi-family housing had met with NIMBYism. This required both design and programmatic elements that would engage neighbors in a welcoming and integrative manner, and was the point that impressed the jury the most. Team PLAN's proposal included 32 two and three bedroom residential units, off-street parking, an on-site childcare facility with a secured outdoor play area, a community room, and a community courtyard.

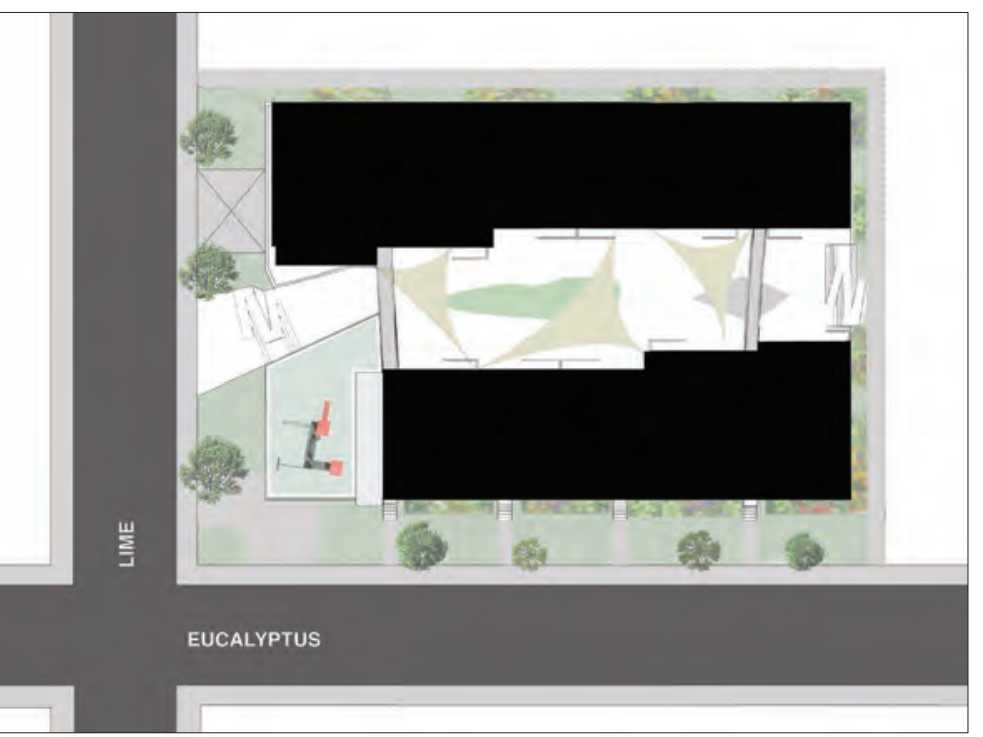

Team PLAN chose to work with a panelized construction system because the smaller size of the development lent itself to using more flexible components. Because of the noise issues, additional sound-proofing measures were required due to the excessive decibel levels at all hours of the day and night. Fortunately, these measures also contribute to green building practices that enhance the project's sustainability goals and a proposed LEED Gold Certification.

Team PLAN's proposal can be found at.google.com/site/planalere/; and the video of the project is at www.youtube.com/ watch? $\mathrm{v}=\mathrm{gcAxilhM} 4 \mathrm{~mA}$

\section{Team ECHO: Sakura Village in San Jose}

Team ECHO (Equitable Concepts in Housing Opportunity) was comprised of Kelly Kha and Mason Hayes (Architecture), Charlie Kokernak (Business Administration), Alex Lim (Construction Management), Parish Burns, Jordan Cowell, and Jared Sammet (CRP), and Paige Pedersen (Landscape Architecture). Working with ROEM Development, a for-profit housing developer, they chose to work on a two-acre site on the edge of Japantown, not far from downtown San Jose, CA.

As with many urban infill sites, Team ECHO's project site was not ideal. Awkwardly triangular in shape, the site is adjacent to an intermittent railroad, so that both building configuration and sound considerations were key issues in determining the density and design of the project. Derek Allen of ROEM Development was a key advisor for both the design and financial aspects of the design. ROEM currently owns the site and had made an attempt at developing it just as the market declined in 2008. Team ECHO wanted a name for its project that both evoked the social history of the area and a sense of order and integration into the current context. Designating the name, Sakura Village, the Japanese word for cherry blossom, was the first step in creating such an identity for the project. Team ECHO had chosen to work with a modular housing builder, Zeta Communities, in order to develop an efficient, zero-waste

Figures $1 \& 2$ :

Team PLAN's proposal. 
building form that would achieve LEED Silver Certification and significantly streamline the construction timeline.

The design includes a mix of 90 one, two, and three bedroom units each with a private balcony. As an integral part of the project, the team proposed a natural playscape area for the younger residents of the building, a community garden, and a community space with an after-school tutoring program for school-aged children. The Natural Playscape is intended to provided a setting for unstructured activities to inspire creative interactions with features such as a music wall, a willow branch tunnel, and a climbing wall, while the after-school tutoring program, developed in conjunction with the School of Education at San Jose State University and LIFESteps, provides K-12 students with an opportunity to sharpen their academic skills.

Team ECHO's proposal can be found at: http://www.calpolyecho.com/; and the video of the project is at: http://www.youtube.com/watch?v=UJcuHLVvHVc.

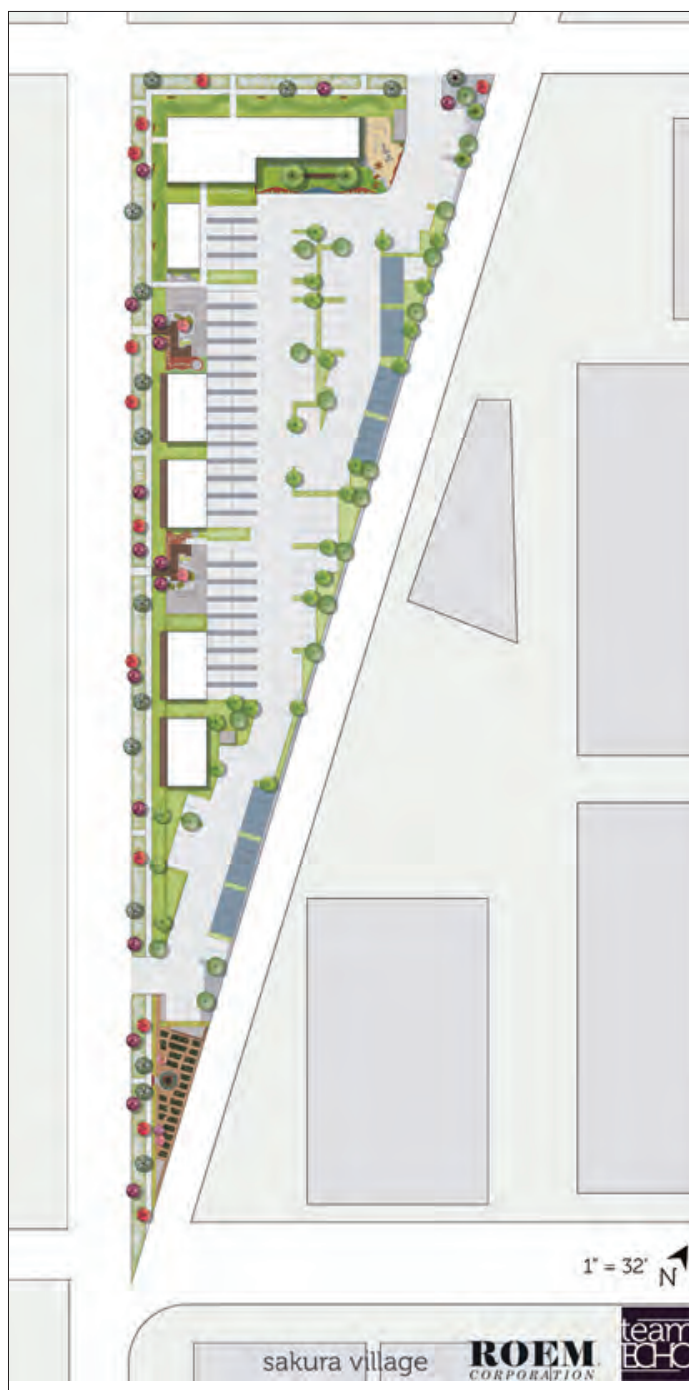

\section{The 2012 Housing Challenge Presentation Day, the Highpoint of the Challenge}

The trip to San Francisco was the culmination of the two-term project. Each team practiced their presentations late into the night, and fueled up on coffee and donuts the morning of the big day. They presented their respective proposals to the attentive jury whose feedback was fair and critical. After an afternoon recess, the teams convened with the other competitors from UC Irvine and UC Berkeley at AT\&T Park for a celebration, tour of the ballpark, and most importantly, the announcement of the 2012 Housing Challenge winner.

After the guest speakers and the showing of each team's video, Matthew Paoni, organizer of the Bank of America/Merrill Lynch Low Income Housing Challenge, announced that Cal Poly's Team PLAN and UC Berkeley's team tied for first place, and noted that each of the entries had addressed community needs (the lack of affordable childcare in Cal Poly's case, and a dearth of community medical services in UC Berkeley's case). While half of the Cal Poly contingency was disappointed with the outcome, all of the students took away with them a new appreciation for the team effort necessary to complete a unique and impressive proposal for housing that addresses so much more than a built form.

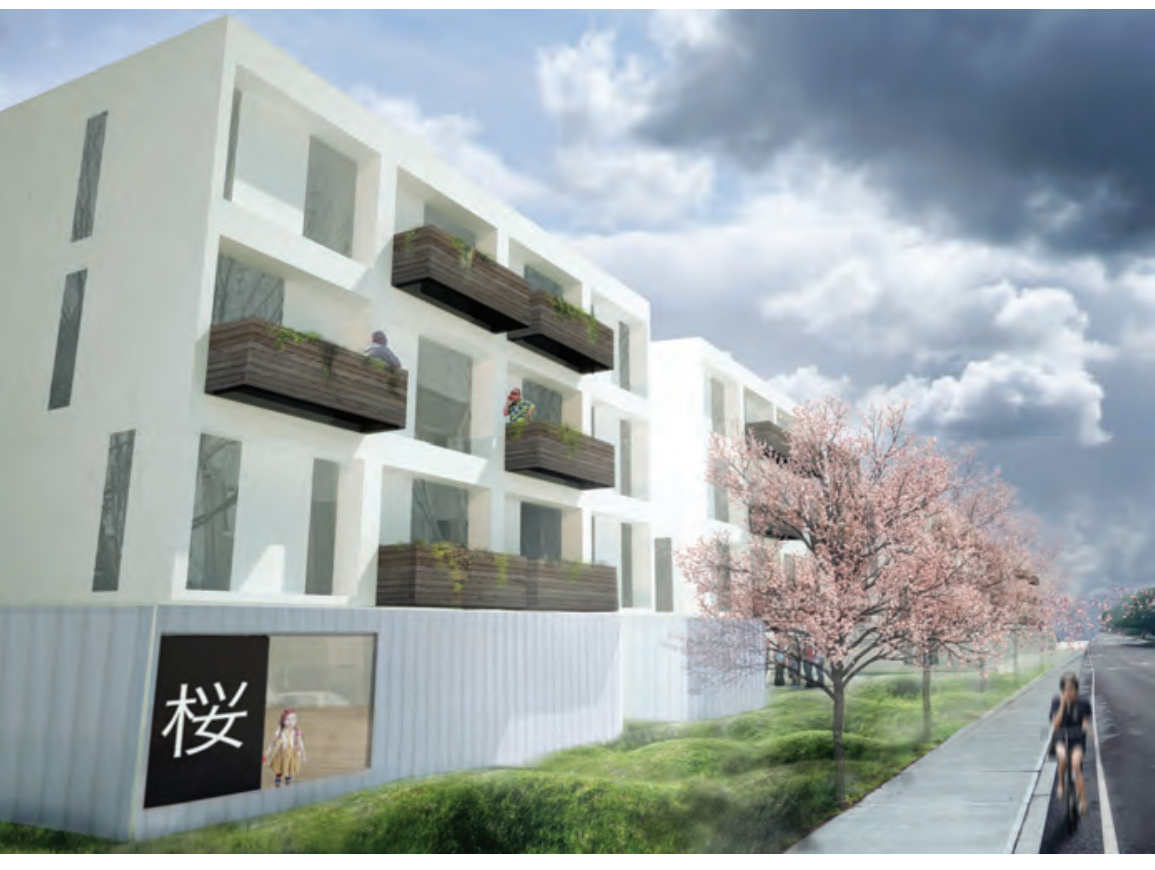

